\title{
Human Resources Evaluation System in the Healthcare Setting: A Qualitative Study in Italy
}

\author{
Varriale Luisa $^{1,}{ }^{*}$, Buonocore Filomena ${ }^{2}$, Briganti Paola ${ }^{1}$ \\ ${ }^{1}$ Department of Sport Science and Wellness, University of Naples "Parthenope", Naples, Italy \\ ${ }^{2}$ Department of Law, University of Naples "Parthenope", Naples, Italy \\ Email address: \\ luisa.varriale@uniparthenope.it (L. Varriale), filomena.buonocore@uniparthenope.it (F. Buonocore), \\ paola.briganti@uniparthenope.it (P. Briganti)
}

\section{To cite this article:}

Varriale Luisa, Buonocore Filomena, Briganti Paola. Human Resources Evaluation System in the Healthcare Setting: A Qualitative Study in Italy. Journal of Human Resource Management. Special Issue: Challenges and Opportunities in the Performance Measurement and Control Systems of Human Resources Management for the Services Industry. Vol. 3, No. 2-1, 2015, pp. 3-10. doi: 10.11648/j.jhrm.s.2015030201.11

\begin{abstract}
In the last thirty years, many reforms have deeply changed the organizational and managerial models adopted in the Italian healthcare system with the increasing adoption of different rules focused on the efficiency and effectiveness standards in the resources allocation. As a consequence, public and private healthcare organizations pay more and more attention to their human resources by searching and implementing different policies aimed to promote, develop and withhold employees with high skills and competences. In this direction, scholars and practitioners significantly and increasingly tend to focus on the evaluation system topic by trying to find the most effective models able to make the employees' performance successful. This paper analyzes the impact of the assessment policies adopted by the organizations on the employees' performance. In this study some relevant factors have been considered, such as the perception of equity by the employees (the concrete care providers), the leadership style, and the perception of wellbeing by the same employees within organizations. This is an exploratory study conducted through a qualitative approach by using a case study methodology. This research is grounded on an in-depth investigation of the private clinic case in the Centre-Southern Italy. This study can extend the previous theoretical and empirical contributions on the evaluation system within healthcare organizations thanks to the adoption of a wide analysis perspective, allowing to focus on aspects usually underrepresented in the existing literature, such as the perception of equity, the level of wellbeing at workplace, and the relational leadership.
\end{abstract}

Keywords: Evaluation System, Healthcare Organizations, Equity

\section{Introduction}

In the last decades, the Italian healthcare system has been deeply changed as a result of the recent reforms which redesign the overall organizational and managerial model, adopting different rules more focused on the efficiency and effectiveness standards in the resources allocation. In this scenario, the healthcare organizations have paid an increasing attention to the human resources management by trying to identify and develop more effective and efficient policies for the planning and management of their employees.

The aim of this study is to investigate the evaluation system in the healthcare setting. More specifically, we analyze the impact of the assessment policies adopted by the organizations on the employees' performance. This analysis considers some relevant factors, such as the perception of equity by the employees (the concrete care providers), the leadership style, and the perception of wellbeing by the same employees within organizations.

In this paper, we draw insight from the organizational literature to investigate what factors may influence the performance of care providers, in details the employees' performance. Otherwise, as a consequence, the employee's performance impacts on the service quality of organizations, because of the direct relationship between employees' performance and organizational performance. In fact, if the employees respect high standards of quality in their work, their performance will be positive, consequently the organization performance, depending on the employees' work, will be perceived and judged successful and satisfying. In this study, we do not investigate the organization performance, but we focus on the employees' performance, adopting an individual level of analysis. Thus, the impact of 
the employees' performance on the organization performance is assumed as given.

This is an exploratory study conducted through a qualitative approach by using a case study methodology. This research is grounded on an in-depth investigation of the private clinic case in the Centre-Southern Italy. Through in-depth interviews realized with the employees of a clinic in the Italian context and by directly observing work processes and activities within the same organization, we present an analysis that identifies in the equity perception, relational leadership and wellbeing the most critical factors ensuring high quality standards for the healthcare organization.

This study can extend the previous theoretical and empirical contributions on the evaluation system within healthcare organizations because it adopts a broad analysis perspective, allowing to focus on aspects usually underrepresented in the existing literature, such as the perception of equity, the level of wellbeing at workplace, and the relational leadership.

\section{Evaluation System in the Healthcare Setting: Main Characteristics and Challenges}

Pay-for-performance (P4P) represents the more widespread system within organizations to support quality improvement of healthcare services, provided by public and private accredited institutions [1].

Different P4P programs may be identified according to the targeted healthcare providers, incentives, and quality measurement criteria. These programs can influence many organizational variables, such as the clinical effectiveness, the access and equity, the coordination and continuity, the patient-centeredness, and the cost-effectiveness. The characteristics of the context, like the healthcare system features, typologies of payer and providers, and patient hallmarks, can significantly mediate the effects of P4P programs [1].

More specifically, regarding the effects on the clinical effectiveness, P4P programs might provide higher levels of performance in chronic care, such as diabetes, coronary heart diseases, asthma, and hypertension care, rather than in preventive and acute care. Moreover, $\mathrm{P} 4 \mathrm{P}$ programs can also positively affect the access and equity of care, by significantly supporting minorities, such as youngest, elderly, female, low educational background, and poorest patients. The implementation of the programs even positively influences the coordination among the healthcare providers, improving the communication processes, and guarantees the temporal and spatial continuity of patients' care, achieving the expected clinical goals. Regarding the patient centeredness dimension, P4P programs show conflicting results especially in the United States healthcare system: most patients experienced no significant improvements reporting low level of satisfaction, maybe because of a ceiling effect. In details, patients do not indeed perceive the positive effect of the healthcare services as formally planned by the P4P programs. In fact, there is a kind of gap between the planning and the managerial phase in the organizational process for the healthcare services. Finally, with reference to the cost-effectiveness, $\mathrm{P} 4 \mathrm{P}$ programs remarkably report consistent savings in costs and, consequently, optimize the resources by reducing costs, not depending on the characteristics of the healthcare context [1].

The implementation of $\mathrm{P} 4 \mathrm{P}$ programs implies very interesting changes in the human resources management for healthcare organizations, especially with reference to the evaluation system adopted by healthcare providers. We observe a relevant shift from "position evaluation" and "fixed compensation" systems, based on the seniority criteria, to "performance assessment" and "non-fixed compensation" systems, focused on the meritocracy.

Within performance appraisal systems, the rater plays a double role as judge and consultant for the human resource development [2]. In fact, the rater acts assuming almost conflicting roles, as two different figures in his/her evaluation activity for the ratee: as a judge by defining the performance in terms of behavior and/or achieved results, observed behaviors, measurable results, and as a coach developing human resource capabilities and planning adequate mobility and career programs.

In the literature several methods of behaviors performance appraisal have been identified, that is the critical incidents (workers' description of significant behaviors in specific job situations), check lists of the specific skills or aspects (identification of different levels of skills and aspects occurred in workers' behaviors), appraisal scales (definition of standards, forced choice, linear, in couple schemes), behaviorally anchored rating scales (B.A.R.S.). Instead, regarding the methods of results performance appraisal, we can distinguish the management by objectives (M.B.O.), planning and revision of the job, balanced scorecard [2].

In the healthcare setting, directors named as judge of their subordinates and peers through performance appraisal methods face numerous challenges because of the specific negative aspects related to the evaluation system. For instance, they outline that the evaluation process requires long timing schedules to make interviews and complete appraisal forms, and consequently an adequate training on managerial competences. Also, the directors playing a rater role complaint that the evaluation is less objective because of the significant influence by subjective characteristics and emotions of the judge. For instance, the directors fear to be disapproved by their colleagues for negative appraisals and to be influenced by affective and previous relational experiences with workers. Otherwise, this situation may worsen also because of the discrepancy in following the procedures by different raters, even considering the control of raters by higher hierarchical level or external actors, the low rate of corrective interventions by organization following the appraisals [3].

Responding to the inefficiencies and limits of performance evaluation systems in the healthcare settings, as above briefly 
described, according to the regulatory system scholars evidence that the equity in the performance appraisal mainly is the result of specific interventions and conditions, such as the adequate communication between all the actors (rater, ratee, organization), the neutrality during appraisal interviews, the judgments based on evidences addressed to the human resources development [4], [5], [6]. Numerous raters experience a conflict between "disciplinary judge" role and "consultant/helpful counselor/coach" role, and they express many doubts about the standardization of appraisal methods, not depending on the characteristics of the context, which are very different within organizations of the same healthcare setting or within units of the same healthcare structure. Indeed, the stating of rules does not represent a sufficient condition to guarantee the performance appraisal efficacy and equity perception [5].

The described positive performance evaluation system is mainly suggested in any kind of organizational models adopted in the healthcare field, especially in the magnet hospital model [7], that is characterized by the identification of specific factors that make more attractive the same structure in order to retain human resources.

The magnet hospital model underlines that the attractive role of an healthcare structures for their workers has mainly played by the equity perception of performance appraisal system, and the professionals' autonomy. The autonomy is considered essential for the productivity, care quality and human resource well-being: it is articulated in self-governance, decision-making, competence, critical reflection, freedom, and self-control [8].

Another aspect which makes healthcare structures more attractive is constituted by the leadership style [9],[10],[11]: the leaders with relational and global orientation positively impact on the productivity, care quality, and human resource well-being.

Research evidence underlines that leaders have a crucial effect on organizational outcomes through individual performance [12]: a clear leadership and supervisory and support processes could positively affect individual performance by improving the job satisfaction, organizational commitment, team working and also promoting psychological distress for patient effective care [13]. Managing relational and technical aspects of workers performance, effective and global leaders are able to clarify some themes, like: creating alignment around sharing objectives and strategies; stimulating enthusiasm, optimism and confidence about success; helping people to positively appreciate each other and to solve problems on technical matters; helping workers to coordinate activities, develop skills, improve flexibility; sharing a common interest aligned to the organization; establishing trust with external stakeholders and patients and families caregivers; creating a shared common sense of identity [14].

According to the demand-control model of job strain [15], high levels of workers' decision latitude and social support at work, that is the autonomy and relational and global leadership processes, could significantly moderate the effects of high psychological demands. Indeed, in the healthcare organizations, long hours, workload, pressure, lack of control over work and poor support by the managers are the most common negative work factors associated with inequity perceptions at work, job dissatisfaction, and psychological ill-health [16].

\section{Methodology}

In this descriptive and exploratory research we adopt a qualitative approach by using a case study methodology. In fact, in the healthcare context the qualitative research can offer significant and numerous methods for identifying what really matters to patients and care providers (nurses, doctors, professionals, and so on), by allowing us to detect and manage the main obstacles in order to change performance and explaining the reasons of improvement or not [17]. Qualitative research has been increasingly used to investigate the quality of healthcare; more specifically, qualitative methods can better understand within healthcare organizations how we can improve employees' performance, and consequently patients' satisfaction and service quality, through adequate decisions in terms of evaluation system or incentive models for the staff.

Our study is grounded on an in-depth investigation of one private healthcare clinic, the "Clinica Alpha". The case study methodology has long been applied in the healthcare context especially in the management research. Thanks to the case studies we can clearly separate a phenomenon from its context, so that only few very important and significant variables can be deeply investigated [18].

This methodology allows observing complex phenomena, such as the healthcare performance, the healthcare service quality, and so on, and identifying the main factors that can affect the success and/or failure of the healthcare organizations, especially in terms of human resource management process within these institutions.

In our paper we collect data combining different qualitative methods, including semi-structured interviews, observation and analysis of documents (archival analysis).

In the qualitative research individual interviews represent the most widely-used data collection method [19],[20]. In fact, individual interviews are typically chosen by scholars to collect detailed accounts of participants' thoughts, attitudes, beliefs, and knowledge pertaining to a given phenomenon [21],[22],[23]. More in details, semi-structured interviews based on a flexible topic allow providing a loose structure of open ended questions to explore experiences and attitudes.

Likewise, the observational method of organizational settings, team behavior, and interactions is very useful in studying quality issues by uncovering everyday behavior and processes. Thus, these methods are increasingly used in the study of organization and delivery of care [24], especially in healthcare settings, for example, investigating everyday work and formative evaluation of services.

We executed our research in several stages. We firstly carried out a literature review on healthcare setting focusing 
on some specific issues, such as the evaluation system adopted to the care employees and the wellbeing within these organizations in order to determine the crucial factors influencing their perception in terms of equity and personal wellbeing of the organization and its evaluation system. Secondly, we conducted semi-structured interviews with 50 employees within the clinic investigated in order to discuss with them the evaluation system applied by the employer so to evidence the relevance of some specific factors and identify new ones. Further, we had access to the documentation illustrating the organization of the clinic and its main human resource management policies, especially the evaluation system and the incentive model. Lastly, we had the opportunity to directly observe several activities and work processes within the clinic.

Our information was obtained mainly through formal semi-structured interviews with employees within the clinic investigated. Our face-to-face semi-structured interviews were organized around a set of predetermined open-ended questions, with other questions emerging from the dialogue between interviewer and interviewee/s. We carried out 50 interviews with key actors at different levels of the clinic, including physicians, doctors and operators. The interviews dealt with a wide range of aspects related to the clinic organization, anecdotes of the main challenges encountered during the services provided, and description of the evaluation system and in general human resources management policies adopted. Interviews lasted on average 40 minutes and were carried out with individuals in their offices or via Skype after an invitation sent via email. All the interviews started with a presentation of the research goals and team members, and an invitation for participants to briefly describe their role and involvement in the organization of the clinic. Then, we asked participants to describe their experience in the clinic and illustrate relevant anecdotes related to their job. Afterwards, we invited participants to response to closed questions about critical factors investigated related to the evaluation system in the clinic, more specifically we presented questions about the perception of equity, the job satisfaction, the level of wellbeing, the relational leadership of the employees' boss. All the open ended questions (item scales), have been evaluated on a Likert scale ranging from 1 (strongly disagree) to 6 (very much in agreement). When necessary, participants could also explain with examples their own experience and status at the workplace.

We also integrated information collected from the interviews with notes that the researchers personally reported during their observations of activities and ordinary processes at workplace, and after reading the documentation gathered in the organization including reports, official and unofficial memos, guidelines and organization charts. We incorporated this documentation with interview responses to have a better view of the phenomenon investigated and crucial factors influencing its success regarding the evaluation system and enhance the reliability of the research [25].

\subsection{Case Study Description}

The private healthcare clinic "Clinica Alpha" was founded in 1928 in Italy, representing for a long time a very valuable health institution among private organizations within a geographic area where public hospitals were still absent. For many years the clinic has provided surgical and specialist care services to the citizens in a wide area, also thanks to the advice and consulting by high profile professionals in the scientific academia. In 1944, because of the war the clinic was completely destroyed, after having served, with its structures support and any kind of medications to the victims of numerous bombings. In 1946, the clinic opened its temporary structure in another area in the Centre-Southern Italy in the waterfront. Here it was created a special section for the treatment of extra lung specific diseases, in which sick patients from Southern regions were hospitalized. In 1964 the clinic moved into new and contemporary premises built following the main principles of medical technology and updated with every possible comfort for the patients. Health facilities are very efficient and updated; the staff is adequately trained, always courteous and professionally qualified. The health structure (with 120 beds) is located in a large green park very comfortable, relaxing and resting for the patients.

The structure provides specific services to its patients at the following operating units: medicine, pneumatology, general and laparoscopic surgery, orthopedics and traumatology, ophthalmology, urology, gynecology, surgery day hospital. In the structure also the ambulatory activities are provided: Cardiology, surgery, angelology, dermatology, digestive endoscopy, hematology, physiotherapy, gynecology, gastroenterology, internal medicine laboratory analysis, endocrinology, neurology, ophthalmology, orthopedics, psychology, pulmonology, radiology, mammography, urology.

In 2013 the clinic was permanently accredited by the local healthcare service (Region healthcare service within the wider National healthcare service system), that is the performance can be carried out both privately and fully covered by the National Health Service (NHS). The remuneration system is linked to the national public tariff DRG (diagnosis related groups) and it implies that the clinic budget has to respect specific annual constraints which fix payable maximum services by the public healthcare system.

In the clinic in total 150 employees and private professionals work, mostly employees with permanent job contract.

In the public healthcare organizations patients usually have to wait for a long time before receiving the services they need, sometimes also many months, the same services can be provided from private structures by 48 hours by satisfying the patients. In this scenario, we can observe that the described conditions of the healthcare system clearly facilitate the creation and recognition of high income and revenues for the private structure and in general for all the operators who are more stimulated to work in the private 
scheme respecting specific the contract rules.

The incentive systems are tools that can increase the likelihood that individuals spontaneously seek and repeat the behavior for achieving the fixed organizational goals. Regarding the medical employees specializing in non-surgical activities, the rewarding model concerns the percentage, of all healthcare activities taken place in the private or not affiliated with the NHS; this percentage varies in the range between $10 \%$ and $30 \%$.

With reference to the operating personnel (nurses, auxiliaries, porters, receptionists, and so on) of the company, we observe that there is no one type of incentive mechanism applied. In fact, the latter are subjected to the national collective agreement of work for employees of the structures associated to the AIOP and Aris associations and Don Carlo Gnocchi Foundation. Every year the members-administrators can make a decision about the deployment of profit.

\subsection{Findings and Discussion}

We interviewed 50 individuals, mostly female employees within the clinic ( 43 women and 7 men), the interviewed individuals were mainly under 30 years old (33 individuals vs. 10 individuals in the age range $31-40$ years old). Moreover, we observe that in our sample 25 employees had as a permanent job contract as a temporary job contract.

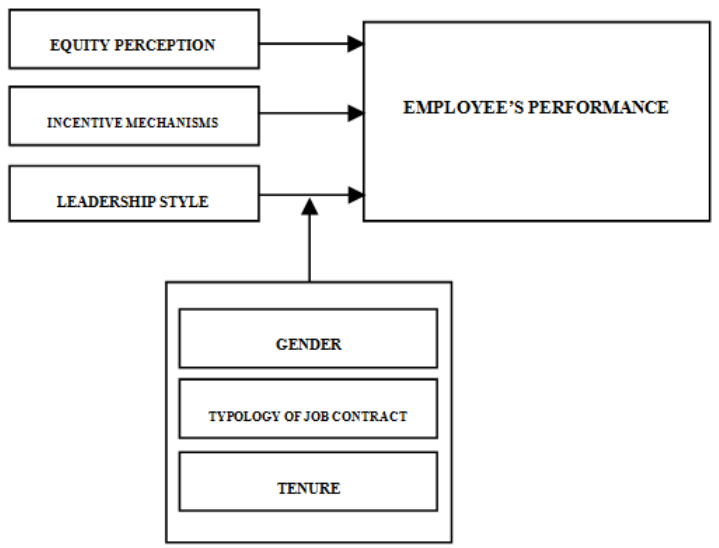

Figure 1. Analysis Model Design.

We conducted a correlation analysis of the responses collected during our semi-structured interviews using the SPSS program, that is a software package used for statistical analysis. More in details, we easily calculated binary correlations of aggregate variables. In fact, this simple analysis aims to determine if the variables investigated in our healthcare organization are linearly related to each other, more specifically we analyze the correlation between the following couples of variables investigated: the equity perception of the performance appraisal system (PAS) and the employees' performance; the incentive mechanisms and employees' performance; the relational leadership style and the employees' performance and, also with minor reference to the equity perception, work satisfaction and wellbeing at workplace. Furthermore, we investigate these binary correlations considering the impact of gender, typology of job contract and tenure of the employees at workplace. More specifically, we analyzed whether these last variables (gender, contract typology, and tenure) can positively or negatively moderate the direct relationship (positive or negative) between the first group of variables (equity perception, incentive mechanisms, and leadership style) and the employee's performance (see Figure 1).

Regarding the results of our main open ended questions, in the case of the perception of the organization in terms of equity and quality standards (equity perception) by the interviewed employees (item scale "My organization applies an incentive mechanism") and about the perception of the own performance by the same individuals, the average of the responses of both item scales (my organization and my performance) is 4 on a Likert scale ranging from 1 (strongly disagree) to 6 (very much in agreement), it means that on average the individuals mostly feel comfortable with their organization and are satisfied regarding their performance within the organization, in fact, they perceive that the organizational goals are clear and also they feel that the top management share all the decisions about the evaluation system adopted. In this case, we can evidence that it exists a significant and positive relationship between the equity perception of PAS and the employee's performance within the organization.

In the category regarding the incentives, the values are always 4 except for the items 7,8 and 9 , respectively concerning "The incentive mechanism creates competition between my colleagues and me", "The incentive mechanism creates organization and cooperation between my colleagues and me", "I would like that the concrete incentive mechanism applied in my company can be changed". In which the value drops to 3 that is in the negative part of the scale. The item scale about "desired own incentives" regarding the expectations regarding their own incentives, more in details about how each employee wants his/her incentive values of some items on average rise up to 5 in the first two questions back at 4 in the other only in the 5 and 7 down to 3 . These results show that the employees interviewed are overall satisfied and perceive the incentives they receive mostly almost corresponding to their expectations.

Furthermore, linked to the incentive mechanisms variable, we analyze the organizational functioning, in fact, for the item scale regarding the operating of the organizational system, the average values go back to 4 . Also the item scales about the relationship between the boss and the professional development, we observe the same result about the perception of the boss for the own professional (career) development.

The item scale $\mathrm{Q}$ about the perception of boss' equity has average values of 4 except for the last question that averages 5 . This result shows that the employees in our sample outline a positive perception of equity by their boss.

With reference to the "relational leadership" item scales, the aggregated group shows an average value of 4 on all the items, that is the employees are overall satisfied about their direct boss, in fact, they explain that their boss tends to 
stimulate their participation, can effectively manage conflicts or gives trust and maximum respect. Thus, we can evidence that there is mainly a positive relationship between the relational leadership style and employee's performance in the clinic investigated. As shown in the table 1, we calculated the binary correlations considering for each specific variable investigated its aggregate value. The results clearly evidence a positive relationship between the equity perception of PAS and the employee's performance, including the organization system in general; also, similar results are shown considering the perception equity of the boss and the relational leadership. On the other side, the results show that no significant relationships have been found between incentive mechanisms (also desired incentives) and employee's performance.

Table 1. Binary correlations of aggregate variables.

\begin{tabular}{lllll}
\hline & \multicolumn{2}{l}{ PERFORMANCE } & & \\
\cline { 2 - 5 } & COEFFICIENT & REGRESSION COEFFICIENT (\%) & $\begin{array}{l}\text { t value (threshold 3 in } \\
\text { absolute value) }\end{array}$ & SIGNIFICANT (Yes/No) \\
\hline $\begin{array}{l}\text { Organization System } \\
\text { Equity Perception }\end{array}$ & 0,956 & 71,4 & 10,95 & Yes \\
Incentive Mechanisms & 0,687 & 42 & 5,9 & Yes \\
$\begin{array}{l}\text { Incentive Mechanisms (how I } \\
\text { would my incentives to be) }\end{array}$ & 0,244 & 9 & 2,18 & No \\
$\begin{array}{l}\text { Operating system } \\
\text { Boss and professional }\end{array}$ & $-0,199$ & 3,4 & 1,3 & No \\
development & 0,644 & 46,1 & 6,41 & Yes \\
Relational Leadership & 0,679 & 53,4 & 7,41 & Yes \\
\hline
\end{tabular}

According to the aggregate group it would seem that the group is sufficiently satisfied with the leadership style, organization, incentives, performance and equity.

If we consider the responses separately on the basis of the gender, more specifically if and how gender variable can moderate each relationship (equity perception/incentive mechanisms/leadership style and employee's performance), we observe not relevant differences, except to the questions related to "I would like an incentive mechanism based on the group performance" and "I would like an incentive mechanism with implications on holidays" on the clarity of the incentives, women mainly respond 4 while men respond 3 , that is the incentive mechanism was more clear for women than for men, in fact, in the question "I would like that the incentive mechanism was modified" men respond positively with a 4 while women would not be happy and meet 3 (almost disagree). This result can support the moderator role of gender mostly in the direct relationship between incentive mechanisms and employee's performance. In addition, for the question "I'd rather an incentive mechanism that affect on advancement of my career", both women and men respond positively but women with greater conviction with the value 5 against 4 for men. Similar results we can observe with the question "I would be happy to have a salary more uncertain, but more related to my performance", where women negatively respond with 3 (more in disagree) with 4 men (almost completely in agree). In the category of the item scales related to the operating of the organizational system, both women and men are also satisfied. In this case, the gender does not significantly affect the relationship between the equity perception and employee's performance.

We can find similar results considering the item scales about the relational leadership, and the influence of the boss on the own improvement and professional development. Excluding item "My boss recognized my good job", where men and women have negative opinions, for all the other items both men and women have similar judges, women always express value 4 while men pushing value 3 on the negative side of the responses scale. Therefore, gender does not significantly moderate the recognized and positive relationship between the relational leadership style and the employee's performance.

Regarding the equity item scales, the scenery does not consistently change, women and men all seem basically satisfied for the perceived fairness; for instance, at the item "I estimate my boss and I consider him/her a competent and worth person" women may express 5 (completely agree) while men remain on 4 but they are all satisfied.

In response class on the relational leadership mean values of the responses are kept on 4 while the only question that differs is the item "My boss is carefully each of us", where women response is 4 while men respond 3 (almost completely disagree). Regarding this item scale men and women's opinions do not significantly differ. In other cases the responses diverge as in the case of item scales "The goals achieved by my organization are clear" and "My boss encourages the participation of all workers in decision-making of my working group". Men evidently feel more encouraged and have a better perception about the results of the organization than women. This correlation does not have large detachments for men and women.

Furthermore, analyzing the correlation between equity and perception of the organization, the results seem obvious, for women the vision is almost homogeneous, in fact, they overall believe that their leader acts fairly, while men who do not know the strategies believe that their boss is not fair. In addition, the employees interviewed, especially females, mainly perceive high level of equity in their management by the organization also in terms of incentive mechanisms applied. Otherwise, the employees, especially males, do not recognize their specific work contribution to the organization performance and, also, consider their leader not very effective in managing problems and conflicts at workplace.

In addition, all the employees, above all women, have a 
positive opinion of their leader, judged fair, also because the boss encourages information sharing among the members of the work group. We would say that women judge in a more positive way their leader, perceiving higher level of equity, than men who do not always agree with them.

Besides, thanks to the information collected during the interviews, we can evidence that most employees interviewed, also thanks to their open comments, consider very important the leadership style adopted by their boss at workplace; they mainly agree with the prevalent literature considering the high impact of the leadership style, more specifically the adoption of a relational leadership style, at workplace, because they can feel more comfortable in providing their performance, they perceive more equity treatment and can share opinions, doubts, and any kind of information regarding the job. Otherwise, the employees also outline their high equity perception of the performance appraisal system adopted in the organization investigated, this result implies relevant positive effects on the workers' performance, and consequently in general on the organization performance, realizing high standards for the performance responding to the quality standards required.

Regarding the impact of gender, typology of contract and tenure of the employees, the analysis does not evidence significant differences, showing that these variables do not significantly moderate and so changes the existing relationship among the variables investigated, also because of the composition of the sample, mostly composed by female workers with permanent job contract and high tenure, so these employees are very close to the organization thanks to their long time work relationship.

In addition, during the indirect observation of several working processes in the organization, we have had the chance to really test the workers' behavior evidencing how they feel at workplace and how some relevant factors, still underrepresented in the literature, impact on their performance. This analysis shows that actually the employees have high performance thanks to their positive equity perception of the performance appraisal (evaluation system adopted by the organization), the good and active relationship with their leader, and consequently high level of work satisfaction and wellbeing at workplace.

\section{Conclusions}

This study can contribute to the existing literature by investigating the way to evaluate human resources in the healthcare organizations, following the effectiveness and efficiency standards as required by the last reforms, through the realization of high levels of employees' performance. In details, we analyze the correlation between the equity perception, leadership style and incentive mechanisms respectively with the employee's performance and the moderator role of factors such as gender, typology of job contract and tenure for the employees performance within a private healthcare organization. Specifically, starting from the traditional human resources management and organizational models, usually applied in the healthcare sector in terms of evaluation system (performance appraisal), this study aims to investigate the implications related to some factors, such as the equity perception or leadership style, on the employees' performance, and consequently the organization performance. According to the existing literature, we argue that the employees can provide high level of performance only if they perceive fair their work environment, they are satisfied, and overall they have positive opinions about their boss, the incentive mechanisms adopted by the organization, and in general the evaluation system implemented. In fact, we try to suggest how knowing the needs of employees, in terms of job satisfaction and their equity perception also related to their leader, it is possible to promote and apply significant interventions aimed to improve the evaluation models more oriented to the same employees. In this case, all the staff in the healthcare sector can improve the own performance with a higher participation and less resistance to change the way to work, following different approaches, more flexible and oriented to the staff personal needs.

The findings of our study can confirm that the interest in this topic is still limited, even though it is increasing in the last decades.

Furthermore, this study presents some interesting managerial implications, because it gives some important suggestions regarding the best way to manage the human resources, considering the assessment model, with more innovative and opened approaches.

This paper presents a review of the contributions in the literature on the human resource evaluation system in the healthcare sector. It is an exploratory study that presents some limitations, of course, for the methodology adopted and the need to deeply investigate the theme. The main limitations are related to its qualitative content and the analysis of only one case study, but it can be considered as an interesting research starting point in order to find new and more intriguing aspects to investigate, which can explain the different solutions to adopt in the healthcare sector, especially to overcome the numerous existing criticisms often related to the resistance to accept specific evaluation models by care providers in this sector.

In the future development of this study, starting from the main criticisms identified in the field of healthcare sector, we might conduct an analysis, also to identify in a wide research design other variables that can be crucial in defining the evaluation system because of their direct or indirect connection to the employees' performance and, of course, we aim to extend the sample by defining a broader quantitative analysis design.

\section{References}

[1] Van Herck, P., De Smedt, D., Annemans, L., Remmen, R., Rosenthal, M. B., and Sermeus, W. Systematic review: effects, design choices, and context of pay-for-performance in healthcare. BMC Health Services Research, 10(1), 2010, 247. 
[2] Tosi, H.L., and Pilati, M. Comportamento organizzativo: persone, gruppi e organizzazione. Egea. 2002.

[3] Towers, Brian, ed. The handbook of human resource management. Blackwell Publishing. 1996.

[4] Wilson, F. "Dilemmas of appraisal". European Management Journal, 20(6), 2002, pp. 620-629.

[5] Redman, T., Snape, E., Thompson, D., and Yan, F.K. "Performance appraisal in an NHS Hospital". Human Resource Management Journal 10(1), 1996, pp. 48-62.

[6] Folger, R., Konovsky, M.A., and Cropanzano, R. "A due process metaphor for performance appraisal". Research in organizational behavior, 14, 1992, pp. 129-177.

[7] McClure, M.L., and Hinshaw, A.S. "Magnet hospitals revisited Attraction and retention of professional nurses". Washington, DC: American Nurses Association. 2002.

[8] Kramer, M., and Schmalenberg, C.E. "Magnet hospital nurses describe control over nursing practice". Western Journal of Nursing Research, 25(4), 2003, pp. 434-452.

[9] Schmalenberg, C., and Kramer, M. "Essentials of a productive nurse work environment". Nursing research, 57(1), 2008, pp. $2-13$.

[10] Flynn, M., and McCarthy, G. "Magnet hospital characteristics in acute general hospitals in Ireland". Journal of Nursing Management, 16, 2008, pp. 1002-1011.

[11] McClure, M.L. "Magnet hospitals: insights and issues". Nursing Administration Quarterly, 29(3), 2005, pp. 198-201.

[12] Michie S., West M.A. "Managing people and performance: an evidence based frame work applied to health service organizations". Journal of Management Reviews, 5/6(2), 2004, pp. 91-111.

[13] West, M.A., Borrill, C.S., Dawson, J.F., Brodbeck, F., Shapiro, D.A., and Haward, B. "Leadership clarity and team innovation in health care". The Leadership Quarterly, 14(4), 2003, pp. $393-410$.
[14] Yukl, G. "An evaluation of conceptual weaknesses in transformational and charismatic leadership theories". The leadership quarterly, 10(2), 1999, pp. 285-305.

[15] Karasek Jr, R.A. "Job demands, job decision latitude, and mental strain: Implications for job redesign". Administrative Science Quarterly, 1979, pp. 285-308.

[16] Williams, S., Michie, S., and Pattani, S. "Improving the Health of the NHS Workforce: Report of the Partnership on the Health of the NHS Workforce". Nuffield Trust. 1998.

[17] DiCicco-Bloom, B., and Crabtree, B.F. "The qualitative research interview". Medical Education, 40(4), 2006, pp. 314-321.

[18] Yin, R.K. "The case study as a serious research strategy". Science communication, 3(1), 1981, pp. 97-114.

[19] Sandelowski, M. "Reembodying qualitative inquiry". Qualitative Health Research, 12(1), 2002, pp. 104-115.

[20] Nunkoosing, K. "The problems with interviews". Qualitative health research, 15(5), 2005, pp. 698-706.

[21] Fielding, N.G., Lee, N.F.R.M., and Lee, R.M. Computer analysis and qualitative research. 1998. Sage.

[22] Speziale, H.J.S. and Carpenter, D.R. "Qualitative Research in Nursing:Advancing the Humanistic Perspective". 3rd edn. Philadelphia, PA: Lippincott, Williams \& Wilkins. 2003.

[23] Loiselle, C.G., Profetto-McGrath, J., Polit, D.F., and Beck, C.T. "Canadian essentials of nursing research". (2nd ed.). New York: Lippincott, Williams \& Wilkins. 2007.

[24] Murphy, L. "Exploring social Interactions of backpackers". Annals of Tourism Research 28, 2001, pp. 50-67.

[25] Yin, R.K. "Case study research: Design and methods". Sage publications. 2014. 